\title{
Intracellular and plasma membrane cholesterol labeling and quantification using filipin and GFP-D4 probes.
}

Lea P Wilhelm ${ }^{1234 \#}$, Laetitia Voilquin ${ }^{1234 \#}$, Toshihide Kobaysahi ${ }^{45}$, Catherine Tomasetto ${ }^{1234^{*}}$ and Fabien Alpy ${ }^{1234^{*}}$

1 Institut de Génétique et de Biologie Moléculaire et Cellulaire (IGBMC), Illkirch, France

2 Institut National de la Santé et de la Recherche Médicale (INSERM), U1258, Illkirch, France

3 Centre National de la Recherche Scientifique (CNRS), UMR7104, Illkirch, France

4 Université de Strasbourg, Illkirch, France

5 Laboratory of Bioimaging and Pathologies, Centre National de la Recherche Scientifique (CNRS), UMR7021, Illkirch, France

\# : these authors contributed equally

* : correspondence to Catherine Tomasetto, IGBMC, 1 rue Laurent Fries, 67400 Illkirch, France; Tel: +33 3886534

24; Fax: +33 3886532 01; email: Catherine-Laure.Tomasetto@igbmc.fr or Fabien Alpy, IGBMC, 1 rue Laurent Fries, 67400 Illkirch, France; Tel: +33 3886535 19; Fax: +33 3886532 01; email: Fabien.Alpy@igbmc.fr

Keywords: Cholesterol; perfringolysin O; filipin; plasma membrane; endosome

\begin{abstract}
Cholesterol, a major component of biological membranes, is rapidly trafficked and unevenly distributed between organelles. Anomalies of intracellular cholesterol distribution are the hallmark of a number of lysosomal lipid storage disorders. A major methodological obstacles for studying cholesterol trafficking is tracing this molecule in situ. The use of fluorescent probes that specifically bind cholesterol, allows the visualization and imaging of cellular cholesterol. Here, we describe a series of assays optimized for quantifying free cholesterol in cell populations and at the single cell level, both at the plasma membrane and inside cells. These methods use two fluorescent probes: the D4 fragment of perfringolysin O fused to GFP (GFPD4); and the polyene macrolide filipin. First, we report a robust method for quantifying plasma membrane cholesterol by flow cytometry using the GFP-D4 probe. Second, to optically distinguish and quantify intracellular cholesterol accumulation, we have adapted the classical filipin cholesterol staining protocol. Indeed, we observed that treatment of living cells with methyl- $\beta$-cyclodextrin, a chemical known to extract cholesterol from the plasma membrane, improves the visualization of the intracellular cholesterol pool with filipin. To complement these staining procedures, we developed an image analysis protocol based on image segmentation to quantify, in a robust manner, intracellular cholesterol stained with filipin. Thus, this chapter is a guideline for cellular cholesterol staining and signal quantification.
\end{abstract}




\section{Introduction}

Cholesterol is a key molecule in biology, as a major structural component of cell membranes, and as a precursor of other vital compounds, such as hormones and bile [1, 2]. Interestingly, sterol levels are regulated at the subcellular scale. Indeed high, intermediate, and low levels of sterol are found in the plasma membrane, endosome/Golgi apparatus, and mitochondria/endoplasmic reticulum, respectively [3, 4]. This uneven sterol distribution between organelles results both from vesicular and non-vesicular transport mechanisms [5]. In particular, a class of proteins named Lipid Transfer Proteins (LTPS) plays a crucial role in the latter process. LTPs are cytosolic proteins which have a pocket that accommodates a lipid molecule; LTPs can capture, move, and deliver this lipid molecule within the cell [6-8]. The study of sterol transport inside cells faces a major obstacle, which is the ability to trace this type of molecule in situ. However, the use of natural fluorescent sterols that closely mimic cholesterol, fluorophore-labeled sterols, or fluorescent probes that can trace cholesterol distribution in cells, have advanced the understanding of sterol transport [9]. In this chapter, we describe the use of two fluorescent probes, GFP-D4 and filipin, to label and quantify plasma membrane and intracellular cholesterol levels.

The GFP-D4 probe is a fusion between the fluorescent protein GFP and the D4 fragment of perfringolysin $\mathrm{O}$ (referred to as $\theta$ toxin), a pore-forming toxin from the bacterium Clostridium perfringens. Perfringolysin $O$ is a cholesterol-dependent cytolysin secreted as a water-soluble monomer that recognizes and binds cholesterol-rich membranes where it oligomerizes and creates pores. The D4 fragment of perfringolysin $\mathrm{O}$ is able to bind cholesterolrich membranes (>30 mol\% cholesterol) but is devoid of pore-forming activity [10-13]. Interestingly, mutants of GFPD4, able to bind membranes with less cholesterol, have been generated $[14,15]$. In this chapter, we describe the use of recombinant GFP-D4 to stain intracellular cholesterol, and to label plasma membrane cholesterol followed by its quantification by flow cytometry.

Filipin is a polyene macrolide extracted from the bacterium Streptomyces filipinensis $[9,16]$. Filipin is naturally fluorescent and specifically binds to sterols but not to esterified sterols. Owing to its toxicity, filipin is used on fixed cells. The use of filipin to label and quantify intracellular cholesterol is technically challenging: first, the probe is very sensitive to photobleaching which impedes its use for quantification; and second, it labels total cellular cholesterol, and especially the plasma membrane, making intracellular cholesterol difficult to image. Thus, to bypass these technical limits, we set up a new protocol, described in this chapter, which allows the imaging and quantification of intracellular cholesterol using filipin [17]. To avoid filipin photobleaching, we used a new generation confocal microscope equipped with a $355 \mathrm{~nm}$ UV-laser and ultrasensitive detectors. In addition, to visualize intracellular cholesterol pools, we treated live cells with methyl- $\beta$-cyclodextrin ( $M \beta C D)$, a molecule able to deplete cholesterol from the plasma membrane [18].

\section{Materials}

\subsection{Chemicals and buffers}

1. U18666A [(3ß)-3-[2-(Diethylamino)ethoxy]androst-5-en-17-one hydrochloride]: $1 \mathrm{mg} / \mathrm{mL}$ in water (stock solution). Store at $-20^{\circ} \mathrm{C}$.

2. Methyl- $\beta$-cyclodextrin (MBCD) solution: Dissolve $660 \mathrm{mg}$ of $\mathrm{M} \beta C D$ powder in $1 \mathrm{~mL}$ of water. Heat at $65^{\circ} \mathrm{C}$ for 15 min to dissolve, and vortex several times. Store this stock solution $(500 \mathrm{mM})$ at $-20^{\circ} \mathrm{C}$. Heat at $65^{\circ} \mathrm{C}$ for $15 \mathrm{~min}$ before use.

3. $\mathrm{M} \beta C D$-cholesterol complex ( $\mathrm{M} \beta C D /$ cholesterol molar ratio: 6.5/1) solution: Dissolve $2.65 \mathrm{~g}$ of $\mathrm{M} \beta C D$ in $25 \mathrm{~mL}$ of buffer (150 mM NaCl, 20 mM HEPES, 1 mM CaCl2, 5 mM KCl, $1 \mathrm{mM} \mathrm{MgCl2,} \mathrm{pH} 7.5$ adjusted with NaOH). Add $0.119 \mathrm{~g}$ of cholesterol powder (Sigma), mix, sonicate 3 times $\left(10 \mathrm{~min}\right.$ each) and heat $\left(15 \mathrm{~min}\right.$ at $\left.65^{\circ} \mathrm{C}\right)$ to solubilize cholesterol. Store this stock solution $(80 \mathrm{mM})$ at $-20^{\circ} \mathrm{C}$. Heat at $65^{\circ} \mathrm{C}$ for $15 \mathrm{~min}$ before use.

4. Phosphate-buffered saline (PBS) 1X: $134 \mathrm{mM} \mathrm{NaCl}, 2.7 \mathrm{mM} \mathrm{KCl}, 8.1 \mathrm{mM} \mathrm{Na} 2 \mathrm{HPO} 4,1.47 \mathrm{mM} \mathrm{KH2PO4,} \mathrm{pH} \mathrm{7.4.}$

5. Paraformaldehyde (PFA) stock solution: $16 \%(\mathrm{w} / \mathrm{v})$ in water (EMS). Store at room temperature (see Note 1$)$.

6. PFA solution (4\% (w/v) in PBS $1 X)$. Mix $10 \mathrm{~mL}$ of PFA stock solution (16\%) with $4 \mathrm{~mL}$ of PBS $10 X$ and $26 \mathrm{~mL}$ of water. Store at $4^{\circ} \mathrm{C}$ (see Note 1 ).

7. Filipin solution. To prepare $50 \mathrm{~mL}$ of filipin solution $(0.1 \mathrm{mg} / \mathrm{ml})$, first dissolve $5 \mathrm{mg}$ of filipin powder in $200 \mu \mathrm{L}$ of dimethyl sulfoxide (DMSO). Add this solution dropwise to $50 \mathrm{~mL}$ of PBS $1 \mathrm{X}$ under constant vortexing. Keep filipin protected from light. Aliquot this solution and store at $-20^{\circ} \mathrm{C}$.

8. $10 \%(\mathrm{w} / \mathrm{v})$ bovine serum albumin (BSA) solution: Dissolve $1 \mathrm{~g}$ of BSA (Fraction $\mathrm{V}$ ) in $10 \mathrm{~mL}$ of PBS $1 \mathrm{X}$. Store the stock solution at $-20^{\circ} \mathrm{C}$.

9. Blocking solution: $1 \%(\mathrm{w} / \mathrm{v}) \mathrm{BSA}$ in PBS $1 \mathrm{X}$.

10. Cell culture medium with and without serum. Trypsin solution ( $30 \mu \mathrm{g} / \mathrm{mL})$ and Trypsin-EDTA ( 30 $\mu \mathrm{g} / \mathrm{mL}-$ $0.53 \mathrm{mM})$. 


\subsection{GFP-D4 production}

1. GFP-D4 expression plasmid (pET28/His6-EGFP-D4; RIKEN BioResource Research Center; RDB13961). This plasmid can be amplified in E. coli DH5 $\alpha$ bacteria.

2. E. coli BL21 (DE3) competent bacteria.

3. LB broth and LB agar plates containing $40 \mu \mathrm{g} / \mathrm{mL}$ kanamycin.

4. IPTG (isopropyl $\beta$-D-1-thiogalactopyranoside): A 1 M stock solution is prepared by dissolving IPTG in water, and stored at $-20^{\circ} \mathrm{C}$.

5. Conical flasks.

6. Lysis buffer: $50 \mathrm{mM}$ NaH2PO4/Na2HPO4, $300 \mathrm{mM} \mathrm{NaCl}, 10 \mathrm{mM}$ imidazole, pH 8. Add $58.25 \mathrm{~mL}$ of Na2HPO4 (0.2 M), $4.25 \mathrm{~mL}$ of NaH2PO4 (0.2 M), $15 \mathrm{~mL}$ of $\mathrm{NaCl}(5 \mathrm{M})$ and $2.5 \mathrm{~mL}$ of Imidazole (1 M) to a graduated cylinder. Add water to a volume of $250 \mathrm{~mL}$, mix and store at $4^{\circ} \mathrm{C}$. Before use, add 1 tablet of EDTA-free complete protease inhibitor cocktail (Roche) in $50 \mathrm{~mL}$ of lysis Buffer.

7. His-Select Nickel Affinity Gel (Sigma).

8. Elution buffer: $20 \mathrm{mM}$ NaH2PO4/Na2HPO4, $250 \mathrm{mM}$ imidazole, $\mathrm{pH}$ 7.4. Add $1.935 \mathrm{~mL}$ of Na2HPO4 (0.2 M), 0.565 $\mathrm{mL}$ of NaH2PO4 (0.2 M) and $6.25 \mathrm{~mL}$ of imidazole $(1 \mathrm{M})$ to a graduated cylinder. Add water to a volume of 25 $\mathrm{mL}$, mix and store at $4^{\circ} \mathrm{C}$.

9. Phosphate buffer (PB): $20 \mathrm{mM} \mathrm{NaH2PO4/Na2HPO4} \mathrm{pH} \mathrm{7.4.}$

10. Ultrafiltration units (Ultra-15 Amicon, MWCO $10 \mathrm{kDa}$, Millipore).

11. Glycerol (molecular biology grade).

12. Sonicator (Sonics Vibra-Cell $750 \mathrm{~W}$ equipped with a $13 \mathrm{~mm}$ probe).

13. Chromatography column (Bio-Rad Poly-Prep chromatography column).

14. Peristaltic pump (Gilson).

15. Spectrophotometer (Nanodrop, Thermo Scientific).

\subsection{Flow cytometry and Imaging}

1. Round cover glasses (diameter $12 \mathrm{~mm}, \mathrm{~N}^{\circ}$. 1.5H).

2. Superfrost microscope slides.

3. 24-well plates

4. P150 plates

5. Propidium iodide (PI) $\left(50 \mu \mathrm{g} / \mathrm{mL}\right.$ stock solution, stored at $\left.4^{\circ} \mathrm{C}\right)$ is diluted in PBS to a final concentration of 0.35 $\mu \mathrm{g} / \mathrm{mL}$.

6. TO-PRO-3 iodide solution: Dilute a $1 \mathrm{mM}$ stock solution in DMSO (ThermoFisher scientific, stored at $-20^{\circ} \mathrm{C}$ ) in PBS to a final concentration of $0.35 \mu \mathrm{g} / \mathrm{mL}$.

7. Hoechst-33258 solution. Prepare a stock solution of the dye at $10 \mathrm{mg} / \mathrm{mL}$ in water. Dilute the dye in PBS to a final concentration of $10 \mu \mathrm{g} / \mathrm{mL}$.

8. Anti-CD63 mouse monoclonal antibody (Developmental Studies Hybridoma Bank (DSHB) H5C6; deposited to the DSHB by August, J.T./Hildreth, J.E.K.). The hybridoma supernatant is diluted 100 times in blocking solution.

9. Mounting medium (ProLong Gold, Invitrogen).

10. Confocal laser scanning microscope (Leica SP8 UV) equipped with a $355 \mathrm{~nm}$ optically pumped semiconductor laser (Coherent), super-sensitive detectors (HyD, Leica) and a 63x objective (oil, NA 1.4).

11. Image analysis software: Fiji software (http://fiji.sc) or CellProfiler (http://cellprofiler.org/)

12. Flow cytometer (BD FACS Celesta) or similar.

13. Flowjo software (FlowJo LLC) or similar.

\section{Methods}

\subsection{GFP-D4 production and purification}

1. Transform competent E. coli BL21 (DE3) cells with the pET28/His6-EGFP-D4 vector according to the manufacturer's instructions.

2. Spread bacteria on $L B$ agar plates with kanamycin and incubate overnight at $37^{\circ} \mathrm{C}$.

3. Transfer one colony to $10 \mathrm{~mL}$ of LB broth with kanamycin. Incubate $16 \mathrm{~h}$ at $37^{\circ} \mathrm{C}$ under agitation.

4. Transfer this pre-culture to a $5 \mathrm{~L}$ conical flask containing $1 \mathrm{~L}$ of $\mathrm{LB}$ broth with kanamycin.

5. Incubate at $37^{\circ} \mathrm{C}$ under agitation. Measure the optical density $(0 D 600 \mathrm{~nm})$ at a wavelength of $600 \mathrm{~nm}$ with a spectrophotometer. When the OD600nm has reached $0.4-0.6$, cool down the culture to $18^{\circ} \mathrm{C}$.

6. Add IPTG to a final concentration of $0.4 \mathrm{mM}$.

7. Incubate under agitation for $16 \mathrm{~h}$ at $18^{\circ} \mathrm{C}$.

8. Transfer the culture medium to centrifugation tubes. Pellet the cells by centrifugation at $3,500 \times \mathrm{g}$ for $15 \mathrm{~min}$.

9. Discard the supernatant. Resuspend the cell pellet in $100 \mathrm{~mL}$ of lysis buffer. 
10. Sonicate the suspension for $10 \mathrm{~min}$ ( $40 \%$ amplitude, on/off cycles $10 \mathrm{~s} / 20 \mathrm{~s}$ ) on ice under constant stirring.

11. Centrifuge twice at $3,500 \times \mathrm{g}$ for $15 \mathrm{~min}$ at $4^{\circ} \mathrm{C}$. Keep the supernatant.

12. Centrifuge twice at $11,000 \times \mathrm{g}$ for $30 \mathrm{~min}$ at $4^{\circ} \mathrm{C}$. Keep the supernatant.

13. Add $1.5 \mathrm{~mL}$ of nickel-charged resin into a chromatography column. Connect the column to a peristaltic pump (see Note 2).

14. Wash the resin with $16 \mathrm{~mL}$ of lysis buffer (flow rate $\sim 1 \mathrm{~mL} / \mathrm{min}$ ).

15. Load the supernatant on the resin (see Note 3).

16. Wash the column with $30 \mathrm{~mL}$ of lysis buffer.

17. Elute the GFP-D4 probe with $6 \mathrm{~mL}$ of elution buffer.

18. The buffer is then exchanged and the probe concentrated with an ultrafiltration unit: first, equilibrate the membrane of a centrifugal filter by adding $5 \mathrm{~mL}$ of phosphate buffer. Centrifuge for $10 \mathrm{~min}$ at 3,500 $\times \mathrm{g}$. Discard the liquid.

19. Add the GFP-D4 probe to the ultrafiltration unit. Spin at 4,500 $\times \mathrm{g}$ for $30 \mathrm{~min}$ in a fixed-angle rotor (see Note 4). Discard the flow-through.

20. Add $7 \mathrm{~mL}$ of PB buffer and spin at 4,500 $\times \mathrm{g}$ for $30 \mathrm{~min}$ (see Note 4). Discard the flow-through.

21. Repeat step 20 in section 3.1 two times.

22. Final spin at 4,500 $\times \mathrm{g}$ and stop when the probe is concentrated in $\sim 1 \mathrm{~mL}$. Recover the probe and measure its concentration with a spectrometer (molar extinction coefficient $\varepsilon 280 \mathrm{~nm}=65,320 \mathrm{M}-1 . \mathrm{cm}-1$; Molecular weight: $42.1 \mathrm{kDa})$.

23. Add $1 \mathrm{~mL}$ of glycerol and store the probe at $-20^{\circ} \mathrm{C}$.

\subsection{Plasma membrane cholesterol staining with the GFP-D4 probe, followed by confocal imaging}

1. Day 0: Plate cells on a glass coverslip (see Note 5 and 6).

2. Day 1: Incubate with the GFP-D4 solution (1: 200 in PBS containing $1 \% \mathrm{BSA}$ ) for 30 min at $37^{\circ} \mathrm{C}$ (see Note 7 and Note 8).

3. Rapid wash with $1 \mathrm{~mL}$ of PBS at room temperature (see Note 9).

4. Fix the cells with $0.5 \mathrm{~mL}$ of PFA solution for $10 \mathrm{~min}$ at room temperature.

5. Wash with $1 \mathrm{~mL}$ of PBS for $5 \mathrm{~min}$ at room temperature.

6. Stain nuclei with the DNA marker Hoechst-33258 for 5 min.

7. Wash with $1 \mathrm{~mL}$ of PBS for $5 \mathrm{~min}$ at room temperature.

8. Mount the sample (see Note 10).

9. Acquire images with a confocal laser scanning microscope equipped with an Argon Laser (488 nm line for GFP excitation) and a 405nm diode laser (Hoechst-33258 excitation) (Fig. 1a).

\subsection{Plasma membrane cholesterol staining with the GFP-D4 probe, followed by flow cytometry analysis}

1. Day 0: Plate 600,000 cells in a P150 plate.

2. Day 1: Rinse the cells with PBS. Trypsinize the cells and resuspend them in $5 \mathrm{~mL}$ of PBS (see Notes 11 and 6).

3. Centrifuge for $5 \mathrm{~min}$ at $230 \times \mathrm{g}$.

4. Resuspend the cells in $800 \mu \mathrm{L}$ of PBS. Aliquot in 3 tubes ( $250 \mu \mathrm{L}$ in each tube) to have a technical triplicate.

5. Add $250 \mu \mathrm{L}$ of GFP-D4 $(10 \mu \mathrm{g} / \mathrm{mL})$ diluted in PBS containing $2 \%$ of BSA in each tube (see Notes 7 and 12$)$.

6. Incubate for $30 \mathrm{~min}$ at $37^{\circ} \mathrm{C}$ under gentle agitation.

7. Fix the cells by adding $500 \mu \mathrm{L}$ of PFA working solution. Mix gently. Incubate $10 \mathrm{~min}$ at room temperature (see Note 1).

8. Pellet the cells by centrifugation for $5 \mathrm{~min}$ at $230 \times \mathrm{g}$.

9. Resuspend the cells in $1 \mathrm{~mL}$ of PBS.

10. Analyze GFP-D4 fluorescence on individual cells by flow cytometry.

11. Single cells are discriminated from doublets using forward scatter height (FSC-H) and forward scatter area (FSCA) measures. FCS-A and FCS-H are plotted and cells along the diagonal are gated. GFP fluorescence is measured on individual cells using blue laser $(488 \mathrm{~nm}$ ) excitation and a FITC filter (band pass filter 530/30 nm). A minimum of 10,000 events must be counted.

12. Analyze the results with Flowjo software: Viable cells are manually gated using SSC (Side-scattered) and FSC (Forward-scattered) parameters. Data are represented as single-parameter histograms showing GFP fluorescence intensity (x-axis) and the number of events (y-axis). The mean of GFP fluorescence is also measured (Fig. 1c, d). 
a

GFP-D4

Plasma membrane staining



C
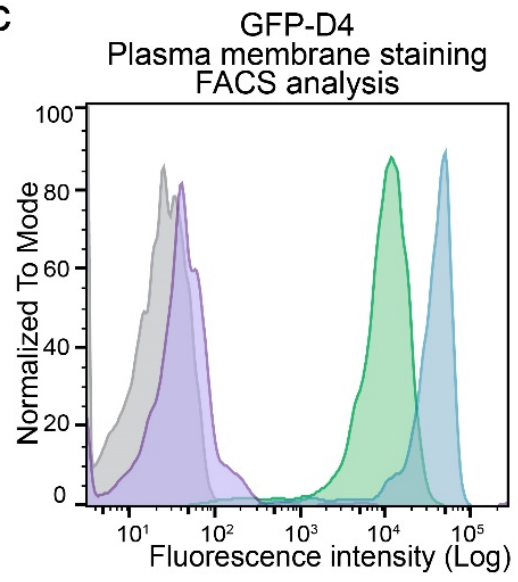

$\square$ HeLa (no probe)

$\square \mathrm{HeLa}$

$\square$ HeLa/M $\mathrm{CD}$ treatment

$\square \mathrm{HeLa} / \mathrm{M} \beta \mathrm{CD}+\mathrm{Cholesterol} \mathrm{treatment}$ b



d


FACS analysis

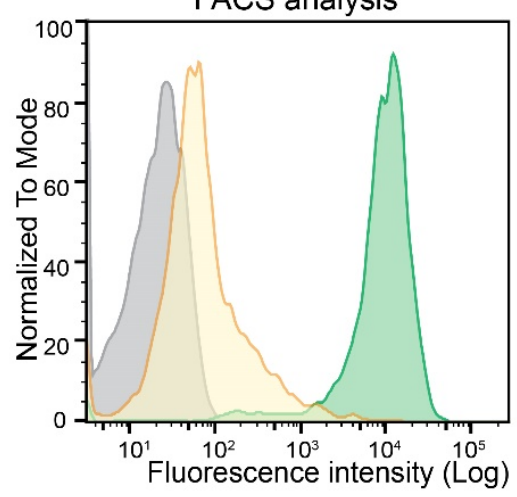

$\square$ HeLa (no probe)

$\square$ HeLa

$\square \mathrm{HeLa} / \mathrm{U} 18666 \mathrm{~A}$ treatment

\section{Figure 1: Plasma membrane and intracellular cholesterol staining with the GFP-D4 probe}

(a) Plasma membrane cholesterol staining of HeLa cells with the GFP-D4 probe. Live cells were left untreated (top image) or treated with $\mathrm{MBCD}$ (10 mM in medium without serum for $30 \mathrm{~min}$ at $37^{\circ} \mathrm{C}$; bottom image), then stained with the GFP-D4 probe and fixed. The nucleus staining is shown in blue. Scale bar: $10 \mu \mathrm{m}$. (b) Intracellular cholesterol staining of HeLa cells with the GFP-D4 probe. Live cells were left untreated (top image) or treated with U18666A $\left(2.5 \mu \mathrm{g} / \mathrm{mL}\right.$ in normal medium for $16 \mathrm{~h}$ at $37^{\circ} \mathrm{C}$; bottom image), fixed, permeabilized, and then stained with the GFP-D4 probe. Nuclei staining is shown in blue. Scale bar: $10 \mu \mathrm{m}$. In panel (a) and (b), a confocal section image and a higher magnification (2.5x) image of the area outlined in white are displayed. (c) Flow cytometry analysis of plasma membrane cholesterol staining with the GFP-D4 probe. Live HeLa cells were left untreated (green curve), or were treated with $\mathrm{MBCD}\left(10 \mathrm{mM}\right.$ for $30 \mathrm{~min}$ at $37^{\circ} \mathrm{C}$; purple curve) or with $\mathrm{M} B C D$ complexed to cholesterol $(500 \mu \mathrm{M}$ for $2 \mathrm{~h}$ at $37^{\circ} \mathrm{C}$; blue curve). (d) Flow cytometry analysis of live HeLa cells which are untreated (green curve), or treated with U18666A $\left(2.5 \mu \mathrm{g} / \mathrm{mL}\right.$ for $16 \mathrm{~h}$ at $37^{\circ} \mathrm{C}$; yellow curve). After the different treatments, the cells were stained with the GFP-D4 probe, fixed and GFP-D4 staining intensity was analyzed by flow cytometry. These representative histograms display the number of cells analyzed (normalized to mode) as a function of GFP-D4 fluorescence (log intensity). Unstained cells (grey curve) are shown. Note that HeLa cells are strongly labeled with the GFP-D4 probe; $\mathrm{MBCD}$ and $\mathrm{MBCD}$ /cholesterol treatments prior to labeling strongly decrease and increase GFP-D4 signal intensity, respectively; U18666A treatment decreases GFP-D4 signal intensity. Indeed, U18666A was shown to induce cholesterol accumulation in the endocytic pathway at the expense of the plasma membrane.

\subsection{Intracellular cholesterol labeling with the GFP-D4 probe}

1. Day 0: Plate $\sim 10,000--15,000$ cells on a glass coverslip (see Note 5 ).

2. Day 1: Wash with $1 \mathrm{~mL}$ of PBS at room temperature for $2 \mathrm{~s}$ (see Note 13).

3. Fix the cells with $500 \mu \mathrm{L}$ of PFA solution at room temperature for $10 \mathrm{~min}$ (see Note 1 ).

4. Wash twice with $1 \mathrm{~mL}$ of PBS at room temperature (5 min). Keep the cells in PBS.

5. Permeabilize the cells using a liquid nitrogen bath: Take the coverslip out of the 24-well plate, remove the excess of PBS and put the coverslip in liquid nitrogen. Wait for $5 \mathrm{~s}$. Place the coverslip back into the 24-well plate in PBS.

6. Incubate with $500 \mu \mathrm{L}$ of blocking solution at room temperature for $30 \mathrm{~min}$, under gentle agitation. 
7. Incubate with the GFP-D4 solution (1:200 in PBS containing $1 \%$ BSA) for 30 min at $37^{\circ} \mathrm{C}$ (see Notes 7 and 12 ).

8. Rapid wash with $1 \mathrm{~mL}$ of PBS at room temperature (see Note 9).

9. Fix the cells with $500 \mu \mathrm{L}$ of PFA solution for $10 \mathrm{~min}$ at room temperature (see Note 1 ).

10. Wash with $1 \mathrm{~mL}$ of PBS at room temperature for $5 \mathrm{~min}$ (see Note 14).

11. Stain nuclei with $1 \mathrm{~mL}$ of Hoechst-33258 solution.

12. Wash with $1 \mathrm{~mL}$ of PBS at room temperature for $5 \mathrm{~min}$.

13. Mount the sample (see Note 10).

14. Acquire images with a confocal laser scanning microscope equipped with an Argon Laser (488 nm line for GFP excitation) and a 405nm diode laser (Hoechst-33258 excitation) (Fig. 1b).

\subsection{Cholesterol labeling with filipin, followed by confocal imaging and image analysis}

\subsubsection{Labeling and image acquisition}

1. Day 0: Plate $10,000--15,000$ cells on a glass coverslip (see Note 5 ).

2. Day 1: Wash twice with $1 \mathrm{~mL}$ of PBS at room temperature ( $2 \mathrm{~s}$ each).

3. In order to facilitate intracellular cholesterol visualization, remove plasma membrane cholesterol with $M \beta C D$ : Dilute the $M \beta C D$ stock 50 times with pre-heated culture medium without serum, to obtain a $10 \mathrm{mM} \mathrm{M} \beta C D$ concentration. Add $500 \mu \mathrm{L}$ of $\mathrm{M} \beta C D$ solution onto the cells, and incubate at $37^{\circ} \mathrm{C}$ for $30 \mathrm{~min}$.

4. Wash twice with $1 \mathrm{~mL}$ of PBS at room temperature (2 min each).

5. Fix the cells with $500 \mu \mathrm{L}$ of PFA solution at room temperature for $10 \mathrm{~min}$ (see Note 1 ).

6. Wash with $1 \mathrm{~mL}$ of PBS at room temperature $(5 \mathrm{~min})$.

7. Incubate with $500 \mu \mathrm{L}$ of filipin solution at room temperature for $30 \mathrm{~min}$, under gentle agitation (see Note 7).

8. Remove the filipin solution and wash cells with $1 \mathrm{~mL}$ of PBS at room temperature for 2 min (see Notes 15 and 16).
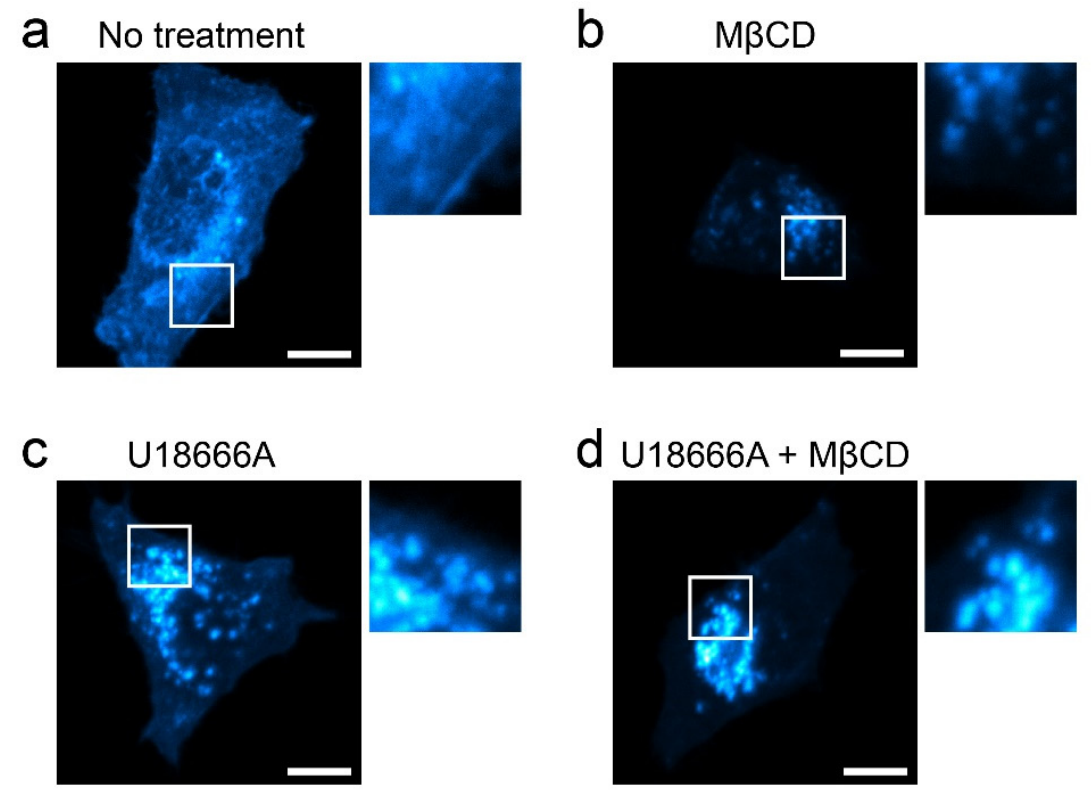

\section{Figure 2: Whole-cell and intracellular cholesterol staining with filipin}

(a). Live HeLa cells were fixed and stained with filipin. (b) Cells were treated with MBCD (10 mM in serum-free medium; 30 $37^{\circ} \mathrm{C}$ ), before fixation and filipin staining. (c) Live HeLa cells were treated with U18666A to induce cholesterol accumulat endosomes/lysosomes before fixation and filipin staining. (d) Cells were treated with U18666A and then with $M \beta C D, 1$ fixation and filipin staining. Each pannel displays a confocal section image and a higher magnification $(2.5 \times)$ image of th outlined in white. Scale bars: $10 \mu \mathrm{m}$. Note that M $B C D$ treatment, by removing cholesterol from the plasma membrane, imf the visualization of intracellular cholesterol pools.

9. Cells are labeled with propidium iodide (PI) $(0.35 \mu \mathrm{g} / \mathrm{mL}$ in PBS) for $5 \mathrm{~min}$, which labels nucleic acids (both DNA and RNA), and thus delineates the cell morphology, an important step for image analysis. Alternatively, cell nuclei are labeled with the DNA marker TO-PRO-3 iodide $(0.35 \mu \mathrm{g} / \mathrm{mL}$ in PBS) for $5 \mathrm{~min}$.

10. Wash twice with $1 \mathrm{~mL}$ of PBS at room temperature ( 2 min each time).

11. Mount the sample (see Note 10).

12. Acquire images with a confocal laser scanning microscope equipped with a $355 \mathrm{~nm}$ optically pumped semiconductor laser to excite filipin. Acquisitions are made using the photon counting mode with a super- 
sensitive detector to decrease light dosage and thus filipin photobleaching (Fig 2). Typically, a single optical section comprising multiple randomly chosen cells is acquired (Fig. 3a).

\section{a Confocal images}



Filipin

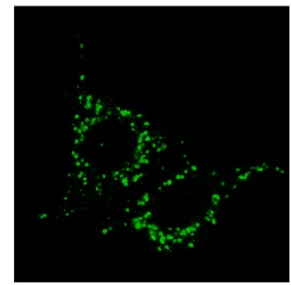

CD63

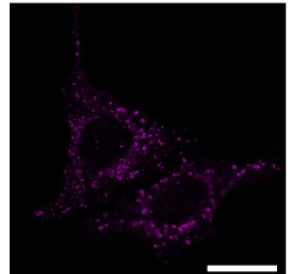

PI

b Image segmentation


of nuclei positions

c Intensity thresholding and filipin quantification

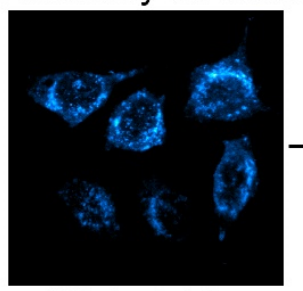

Filipin staining

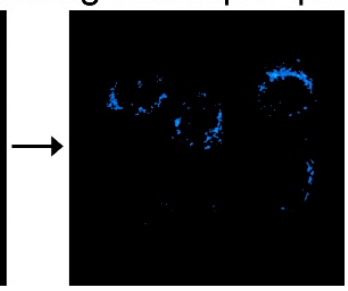

Thresholded image

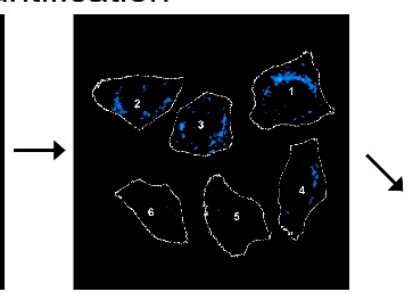

Segmented image






\subsubsection{Quantification of cholesterol in discrete subcellular structures}

We use the Fiji software or CellProfiler to automate the analysis. The quantification of cholesterol accumulation in discrete subcellular structures is based on signal intensity thresholding

1. Individual cells are segmented on images using the PI staining (Fig. 3b). First an intensity threshold is applied to determine the cell contours. Nuclei positions, manually selected on the PI staining image, are used to divide the image into discrete areas with a watershed algorithm (Find maxima). Then, the thresholded and the segmented images are combined to build a segmentation mask showing the contour of individual cells.

2. Apply a threshold value to the filipin image (see Note 17).

3. Then, apply the segmentation mask and measure filipin staining intensity in individual cells (Fig. 3c).

\subsubsection{Quantification of cholesterol in a specific subcellular compartment}

The second method is based on the use of a mask to restrict the analysis to a specific cellular compartment (Fig. $3 \mathrm{~d}$; illustrated with a labeling of late endosomes/lysosomes with anti-CD63 antibodies).

1. Individual cells are segmented as described in step 1 in section 3.5 .2

2. Apply an intensity threshold to the image of the subcellular compartment marker staining.

3. Generate a mask from this threshold.

4. Combine the threshold and the segmentation masks, and measure filipin staining intensity in individual cells.

\section{Notes}

1. Manipulate PFA under a fume hood. Wear protective gloves, protective clothing, and eye protection.

2. Alternatively, use an automated purification system with a pre-packed immobilized metal ion affinity chromatography (IMAC) column.

3. The green color of GFP facilitates the purification since the protein can easily be followed when bound to the resin and during elution.

4. Adjust the centrifugation time to the volume remaining on the filter which should not be lower than $\sim 1 \mathrm{~mL}$.

5. Under sterile condition, put a glass coverslip in each well of a 24-well plate. Add $500 \mu \mathrm{L}$ of pre-heated medium and the cell suspension ( $10,000--15,000$ cells). The confluency should be low (around $20--30 \%$ ) to have isolated cells.

6. For cells which have a tendency to form clusters, trypsin EDTA can be used to detach and dissociate cells before the plating.

7. Protect the samples from light during all steps, once filipin or GFP-D4 has been added.

8. Optional: The cells can be pretreated with $M \beta C D$ to remove cholesterol from the plasma membrane as negative control. Dilute the $M \beta C D$ stock 50 times with pre-heated medium without serum, to obtain a $10 \mathrm{mM} \mathrm{M \beta CD}$ solution in culture medium. Wash the cells twice with PBS. Add $0.5 \mathrm{~mL}$ of $\mathrm{M} \beta C D$ solution onto the cells, and incubate at $37^{\circ} \mathrm{C}$ for $30 \mathrm{~min}$. Remove the $\mathrm{MBCD}$ solution and wash the cells once with PBS.

9. This step allows the removal of the excess probe. Remove the probe solution, add $1 \mathrm{~mL}$ of PBS at room temperature, and immediately remove it. A longer incubation in PBS would enable the GFP-D4 probe to detach from the membrane before the fixation step.

10. Apply a drop of mounting medium on a glass slide. Take out the cover glass carefully from the well, remove the excess PBS, and carefully place over the mounting media with the cells face down. Incubate at least $2 \mathrm{~h}$ at room temperature before use. Slides can be store at $4^{\circ} \mathrm{C}$ protected from light.

11. On Day 1, positive and negative control samples can be obtained by adding or removing cholesterol from the plasma membrane before trypsinisation. Plasma membrane cholesterol levels can be reduced by $M \beta C D$ or U18666A treatment, or increased by $M \beta C D$-cholesterol treatment. $M \beta C D$ treatment: Dilute the $M \beta C D$ stock 50 times with pre-heated medium without serum, to obtain a $10 \mathrm{mM} \mathrm{M \beta CD}$ solution in culture medium; wash the cells twice with PBS; add $5 \mathrm{~mL}$ of $\mathrm{MBCD}$ solution onto the cells and incubate at $37^{\circ} \mathrm{C}$ for $30 \mathrm{~min}$. U18666A treatment: Wash the cells twice with PBS; treat the cells with U18666A $(2.5 \mu \mathrm{g} / \mathrm{mL})$ in normal culture medium for $16 \mathrm{~h}$ at $37^{\circ} \mathrm{C}$. $M \beta C D$-cholesterol treatment: Dilute the $M \beta C D$-cholesterol complex stock 160 times with pre-heated medium without, to obtain a $500 \mu \mathrm{M} M \beta C D$-cholesterol complex solution in culture medium; wash the cells twice with PBS; add $5 \mathrm{~mL}$ of $\mathrm{M} \beta C D$-cholesterol complex solution onto the cells, and incubate at $37^{\circ} \mathrm{C}$ for $2 \mathrm{~h}$.

12. The concentration of GFP-D4 has to be adjusted to the samples analyzed. Increasing the concentration of GFP-D4 will increase the fluorescent signal proportionally. 
13. On Day 1, positive control samples can be obtained by treating cells with U18666A to induce cholesterol accumulation in endosomes. Treat the cells with U18666A $(2.5 \mu \mathrm{g} / \mathrm{mL})$ in normal culture medium for $16 \mathrm{~h}$ at $37^{\circ} \mathrm{C}$, and then wash with PBS.

14. At this step, an immunofluorescence staining can be done to detect the protein of interest in addition to cholesterol.

a) Incubate the cells with $500 \mu \mathrm{L}$ of blocking solution at room temperature for $30 \mathrm{~min}$, under gentle agitation.

b) Add appropriate primary antibody diluted in $250 \mu \mathrm{L}$ of blocking solution, and incubate for $3 \mathrm{~h}$ at room temperature, or overnight at $4^{\circ} \mathrm{C}$, under gentle agitation.

c) Wash 3 times with $1 \mathrm{~mL}$ of PBS (5 min each time).

d) Add fluorescently-conjugated secondary antibodies (Alexa Fluor 488), and incubate $1 \mathrm{~h}$ at room temperature, under gentle agitation.

e) Wash 3 times with $1 \mathrm{~mL}$ of PBS at room temperature (5 min each time).

15. At this step, an immunofluorescence staining can be done to detect the protein of interest in addition to cholesterol.

a) Incubate the cells with $500 \mu \mathrm{L}$ of blocking solution at room temperature for 30 min, under gentle agitation.

b) Add appropriate primary antibody diluted in $250 \mu \mathrm{L}$ of blocking solution, and incubate for $3 \mathrm{~h}$ at room temperature, or overnight at $4^{\circ} \mathrm{C}$, under gentle agitation.

c) Wash 3 times with $1 \mathrm{~mL}$ of PBS (5 min each time).

d) Add fluorescently-conjugated secondary antibodies (Alexa Fluor 488), and incubate $1 \mathrm{~h}$ at room temperature, under gentle agitation.

e) Wash 3 times with $1 \mathrm{~mL}$ of PBS at room temperature (5 min each time).

f) Incubate the cells with $500 \mu \mathrm{L}$ of filipin solution at room temperature for $30 \mathrm{~min}$, under gentle agitation.

g) Wash twice with $1 \mathrm{~mL}$ of PBS at room temperature ( 5 min each time).

16. Since filipin permeabilizes membranes, it allows antibody entry inside cells. Note that only some antibodies work in the presence of filipin; this has to be tested for your specific application.

17. The choice of the threshold value is somehow arbitrary. However, in order to allow a comparison between experiments, the threshold can be determined in control cells (no cholesterol accumulation) as the $99^{\text {th }}$ percentile of pixel intensity values. Evaluate this value for all images of control cells and calculate a mean intensity which will be defined as the threshold value.

\section{Acknowledgments}

We thank Thomas Di Mattia and Alastair McEwen for their critical reading of the manuscript. We thank the members of the Molecular and Cellular Biology of Breast Cancer team (IGBMC) for helpful advice and discussions, and the IGBMC imaging center. L.V. received an allocation from the Ministère de l'Enseignement Supérieur et de la Recherche (France; http://www.enseignementsup-recherche.gouv.fr/) and L.P.W. a fellowship from the Fondation pour la Recherche Médicale (https://www.frm.org/). This work was supported by grants from the Institut National Du Cancer INCA (INCA_9269; www.e-cancer.fr), the Ligue Contre le Cancer (Conférence de Coordination Interrégionale du Grand Est; https://www.ligue-cancer.net), The Ara Parseghian Medical Research Fund (http://parseghianfund.nd.edu/), Vaincre les maladies lysosomales (http://www.vml-asso.org/) and the grant ANR-10-LABX-0030-INRT, a French State fund managed by the Agence Nationale de la Recherche under the frame program Investissements d'Avenir ANR-10-IDEX0002-02. We also acknowledge funds from the Institut National de Santé et de Recherche Médicale (http://www.inserm.fr/), the Centre National de la Recherche Scientifique (http://www.cnrs.fr/), and the Université de Strasbourg (http://www.unistra.fr).

\section{References}

1. Maxfield FR,van Meer G (2010) Cholesterol, the central lipid of mammalian cells. Curr Opin Cell Biol 22: 422-429

2. Mesmin B, Antonny B,Drin G (2013) Insights into the mechanisms of sterol transport between organelles. Cell Mol Life Sci 70: 3405-3421

3. Maxfield FR,Menon AK (2006) Intracellular sterol transport and distribution. Curr Opin Cell Biol 18: 379-385

4. van Meer G, Voelker DR,Feigenson GW (2008) Membrane lipids: where they are and how they behave. Nat Rev Mol Cell Biol 9: 112-124

5. Wustner D, Herrmann A, Hao M et al (2002) Rapid nonvesicular transport of sterol between the plasma membrane domains of polarized hepatic cells. J Biol Chem 277: 30325-30336 
6. Chiapparino A, Maeda K, Turei D et al (2016) The orchestra of lipid-transfer proteins at the crossroads between metabolism and signaling. Prog Lipid Res 61: 3039

7. Holthuis JC,Levine TP (2005) Lipid traffic: floppy drives and a superhighway. Nat Rev Mol Cell Biol 6: 209-220

8. Lev S (2010) Non-vesicular lipid transport by lipidtransfer proteins and beyond. Nat Rev Mol Cell Biol 11: 739750

9. Maxfield FR,Wustner D (2012) Analysis of cholesterol trafficking with fluorescent probes. Methods Cell Biol 108: 367-393

10. Abe M, Makino A, Hullin-Matsuda F et al (2012) A role for sphingomyelin-rich lipid domains in the accumulation of phosphatidylinositol-4,5-bisphosphate to the cleavage furrow during cytokinesis. Mol Cell Biol 32: 1396-1407

11. Ohno-Iwashita Y, Shimada Y, Waheed AA et al (2004) Perfringolysin $\mathrm{O}$, a cholesterol-binding cytolysin, as a probe for lipid rafts. Anaerobe 10: 125-134

12. Rossjohn J, Feil SC, McKinstry WJ et al (1997) Structure of a cholesterol-binding, thiol-activated cytolysin and a model of its membrane form. Cell 89: 685-692
13. Shimada Y, Maruya M, Iwashita S et al (2002) The Cterminal domain of perfringolysin $\mathrm{O}$ is an essential cholesterol-binding unit targeting to cholesterol-rich microdomains. Eur J Biochem 269: 6195-6203

14. Johnson BB, Moe PC, Wang D et al (2012) Modifications in perfringolysin $\mathrm{O}$ domain 4 alter the cholesterol concentration threshold required for binding. Biochemistry 51: 3373-3382

15. Liu SL, Sheng R, Jung JH et al (2017) Orthogonal lipid sensors identify transbilayer asymmetry of plasma membrane cholesterol. Nat Chem Biol 13: 268-274

16. Gimpl G,Gehrig-Burger K (2007) Cholesterol reporter molecules. Biosci Rep 27: 335-358

17. Wilhelm LP, Wendling C, Vedie B et al (2017) STARD3 mediates endoplasmic reticulum-to-endosome cholesterol transport at membrane contact sites. EMBO J 36: 14121433

18. Zidovetzki R,Levitan I (2007) Use of cyclodextrins to manipulate plasma membrane cholesterol content: evidence, misconceptions and control strategies. Biochim Biophys Acta 1768: 1311-1324 